\title{
Experimental Characterization of Rutting Performance of HMA Designed with Aggregate Gradations According to Superpave and Marshall Methods
}

\author{
Basim H. Al-Humeidawi \\ Roads and Transport Engineering Department, College of Engineering, University of Al-Qadisiyah, \\ Al-Diwaniya, Iraq \\ Email: Basim.alhumeidawi@qu.edu.iq
}

Received 2 August 2016; accepted 21 August 2016; published 24 August 2016

Copyright (C) 2016 by author and Scientific Research Publishing Inc. This work is licensed under the Creative Commons Attribution International License (CC BY). http://creativecommons.org/licenses/by/4.0/

(c) (i) Open Access

\section{Abstract}

The permanent deformation (rutting) of pavement is a major distress in flexible pavement. It is related to vehicles properties and/or pavement materials and conditions. This article presents an extensive experimental investigation in order to compare between the aggregate gradation according to Superpave and Marshall methods of asphalt concrete mix design on pavement rutting and to examine the sensitivity of rutting resistance to aggregate gradation. A wheel truck machine has been used for measurement of pavement rutting (permanent deformation). The tests were carried out at two controlled different air temperature $55^{\circ} \mathrm{C}$ and $25^{\circ} \mathrm{C}$. The results obtained showed that the adopting of aggregate gradation procedure of Superpave method of pavement mix design for Marshall method of asphalt concrete mix design can reduce the pavement rutting by about $50 \%$. This achievement may be related to missing of three sieves in aggregate gradation procedure of Marshall method which controls rounded and finer aggregate particles. These sieves provide more continuity for aggregate gradation to ensure filling unnecessary gaps and produce more contact points between the aggregates in Hot Mix Asphalt (HMA). The outputs of the research support modifying Marshall method of asphalt concrete mix design by adopting aggregate gradation proposed in Superpave method. The results of study also showed that the coarser aggregate provided more resistance to pavement rutting.

\section{Keywords}

Superpave, Marshall Method, Pavement Rutting, Aggregate Gradation, Experimental Investigation 


\section{Introduction}

Hot Mix Asphalt (HMA) is one of the most popular types of asphalt pavement design used in different countries around the world. Although, there are several methods for designing HMA, such as Marshall method, Haveem method, and asphalt institute method; the design of these mixes is still rely on the Marshall procedure in several countries [1]. Marshall mix design procedure (ASTM D 1559) [2] is based upon a purely an empirical experimental tests and has a several limitations in detecting the effect of several traffic and environmental factors, and material properties (aggregate and binder) on pavement performance [3].

In recent years, the Strategic Highway Research Program (SHRP) developed a new mix design method namely Superior Performing Asphalt Pavements (SUPERPAVE). This method consists of three main steps: 1) Performance Grade (PG) of binder which depends on a range of degrees of temperature and adjust according to traffic consideration, 2) criteria for aggregate gradation including more restrictions compared with Marshall method, 3) mix design procedure simulates the field conditions and performance tests, consequently; it ties the materials selection to traffic and climates considerations [4]-[6].

The aggregate gradation is an important difference between the Superpave and Marshall methods for design of HMA. Aggregate consists the vast bulk of asphalt mixtures components, generally comprises 92 to 96 percent of the weight of HMA. Several studies had showed that the aggregate gradation is one of most factors affecting permanent deformation (rutting) of pavement [7]-[9]. They showed that the resistance to rutting is highly depending on aggregate gradation.

The permanent deformation (rutting) is one of the major distresses occur in flexible pavement as an accumulative depression pavement in wheel paths of vehicles under traffic load [10]. There are three main factors affecting the occurrence of pavement rutting: climate conditions, traffic considerations, and pavement (materials and design) [11] [12]. In the climate condition aspect, the prevailing degree of temperature has a significant effect on pavement deformation in which the increase in degree of temperature increases the possibility of pavement rutting. Similarly, the increasing of accumulative number of wheels and slow moving vehicle may lead to more pavement rutting. The third important factor involves the materials selection (binder and aggregate) and HMA design [13].

Several researches have been conducted to compare between the Superpave mix design procedure and a traditional procedure of mix design according to Marshall method. The results of these studies revealed that the new design procedure of pavement (Superpave) can attribute to better pavement performance and more longevity [1] [2] [14]-[16]. Most of these studies focused on the effect of these two procedures on design aspects and pavement distresses. Therefore, these researches were always adopted similar mix components to be completely design according to these two methods. Even thought that provided a good indication on the differences in these methods as overall but it may not clearly shows the effect of each parameter in design procedure.

The current research focuses on the effect of aggregate gradation (as one of design parameters) on pavement rutting depth. The aggregate gradations according to Marshall method and the aggregate gradations according to Superpave method were implemented in Marshall method for asphalt concrete mix design to clarify the effect of aggregate gradation on rutting resistance. This allows for modification of the traditional procedure of Marshall method usually used for asphalt concrete mix design.

\section{Materials}

\subsection{Asphalt Binder}

An Asphalt cement 40 - 50 grade (obtained from Nasirya refinery) has been used as binder for all mixtures investigated in this research. The rheological properties of binder were determined according to traditional tests shown in Table 1. These tests involved penetration test, softening point test, ductility test and flash point test. The result of these test are shown in Table 1.

\subsection{Aggregate}

Natural crushed aggregate (available locally-Badra site) with maximum size of $19 \mathrm{~mm}$ was used for all mixes as suitable for binder layer of flexible pavement (SORB/R9) [17]. The gradations of aggregate were design to compare between Superpave and Marshall procedures for designing aggregate gradation in asphalt concrete mixes. Three aggregate gradations were adopted according to Superpave procedure: above the restricted zone 
Table 1. The rheological properties of binder.

\begin{tabular}{|c|c|c|c|c|}
\hline Type of test & $\begin{array}{c}\text { Penetration } \\
\left(100 \mathrm{~g}, 5 \mathrm{~s}, 25^{\circ} \mathrm{C}\right), 0.1 \mathrm{~mm}\end{array}$ & Softening point $\left({ }^{\circ} \mathrm{C}\right)$ & $\begin{array}{c}\text { Ductility } \\
\left(25^{\circ} \mathrm{C}, 5 \mathrm{~cm} / \mathrm{min}\right), \mathrm{cm}\end{array}$ & Flash point $\left({ }^{\circ} \mathrm{C}\right)$ \\
\hline Specification & ASTM D5-13 & ASTM D92-12b & ASTM D113-07 & ASTM D36-12 \\
\hline Result of test & 44 & 51 & $>100$ & 255 \\
\hline
\end{tabular}

(S-AR), through the restricted zone (S-TR), and below the restricted zone (S-BR). Similarly, three aggregate gradations were adopted according to Marshall procedure: upper limit (M-UL), mid-specification (M-MS), and lower limit (M-LL). Figure 1 shows the aggregate gradations according to both Superpave and Marshall methods. From Figure 1, it can be noticed that the discontinuity of Marshall aggregate gradation in fine aggregate zone due to missing of three sieves at this region $(1.18 \mathrm{~mm}, 0.6 \mathrm{~mm}$ and $0.15 \mathrm{~mm})$.

\section{Methodology and Experimental Program}

The research was primarily aimed to study the effect of aggregate gradation on pavement rutting according to Superpave and Marshall methods. Figure 2 shows the research frame work for the entire experimental programme.

\subsection{Optimum Asphalt Contents (OAC)}

Optimum Asphalt Contents (OAC) were determined for each aggregate gradation as shown in Table 2. Five percentages of asphalt content were examined to find OAC starting with $4 \%$ and ending by $6 \%$ at interval of $0.5 \%$, consequently, $90(3 \times 5 \times 6)$ samples were tested for this purpose. The sample of OAC determination is illustrated in Figure 3.

\subsection{Pavement Rutting Testing Machine}

The pavement rutting test has been carried out using wheel track machine manufactured in road laboratory, college of engineering, University of Al-Qadisiyah for the purpose of doing this research and other research in future. The machine consists of metal cabinet with digital control electric heater with heating temperature reached up to $55^{\circ} \mathrm{C}$. Inside the cabinet there is a wheel with frame to carry the desired load and can move up and down only. In the middle of cabinet there is a movable base with five wheels on each side connected to motor with three speeds (34 passes/min., 100 passes/min., and 345 passes/min.). This base moves over two thick plates forward and backward. The mould of specimen is fixed on the movable base after removing the upper part of it. Figure 4 shows the testing machine. A dial gauge is used to measure the depth of pavement rutting after each specific number of wheel passes.

\subsection{Preparing the Specimen}

A mould was design to closely represent the real pavement especially the thickness of pavement layer. The mould consists of three parts: base with clear dimensions of $300 \times 200 \mathrm{~mm}$, lower sides as one piece with height of $30 \mathrm{~mm}$ and upper sides as two pieces with height of $60 \mathrm{~mm}$, consequently the inside dimensions of mould are $300 \times 200 \times 90 \mathrm{~mm}$. The upper part of mould (with height of $60 \mathrm{~mm}$ ) is removed after the compaction of the specimens. Figure 5 illustrates the parts of moulds.

The specimens are prepared according to the each specific aggregate gradation by blending the components according to Marshall procedure described in ASTM D 1559-89. After the completion of blending of component, the specimens is put in the mould for compaction process. The compaction was made by pressing the specimens in universal loading machine. The magnitude of load was determined by compacting several specimens with different load values then selected the value which give similar density to that obtained from Marshall specimens $\left(2.33 \mathrm{gm} / \mathrm{cm}^{3}\right)$. The selected load value $(240 \mathrm{kN})$ was adopted for all specimens. Figure 6 shows the compaction process of specimen, as well as Figure 7 shows the selection of compaction load.

\subsection{Testing of Specimens}

After the completion of compaction process, the upper part of mould was removed and the specimens were left 


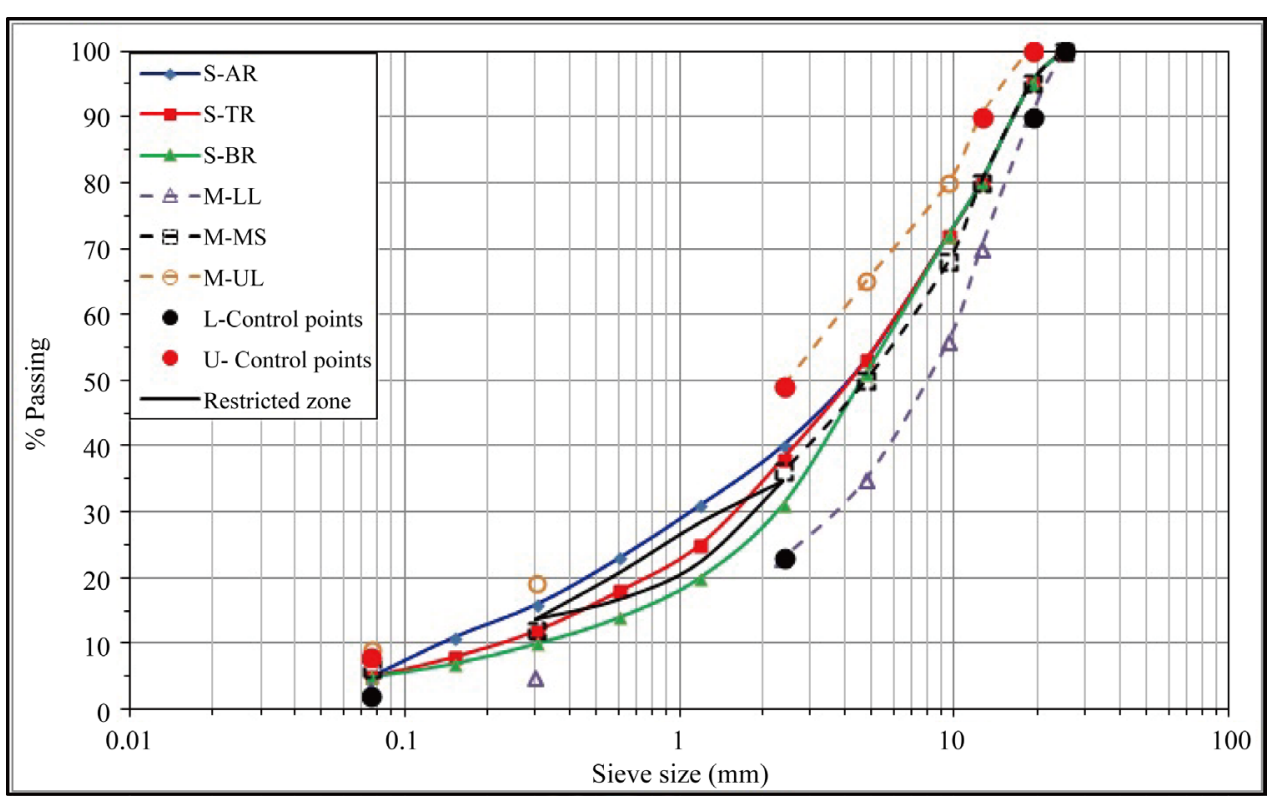

Figure 1. Aggregate gradations according to Superpave and Marshall methods (log scale is used for x-axis).

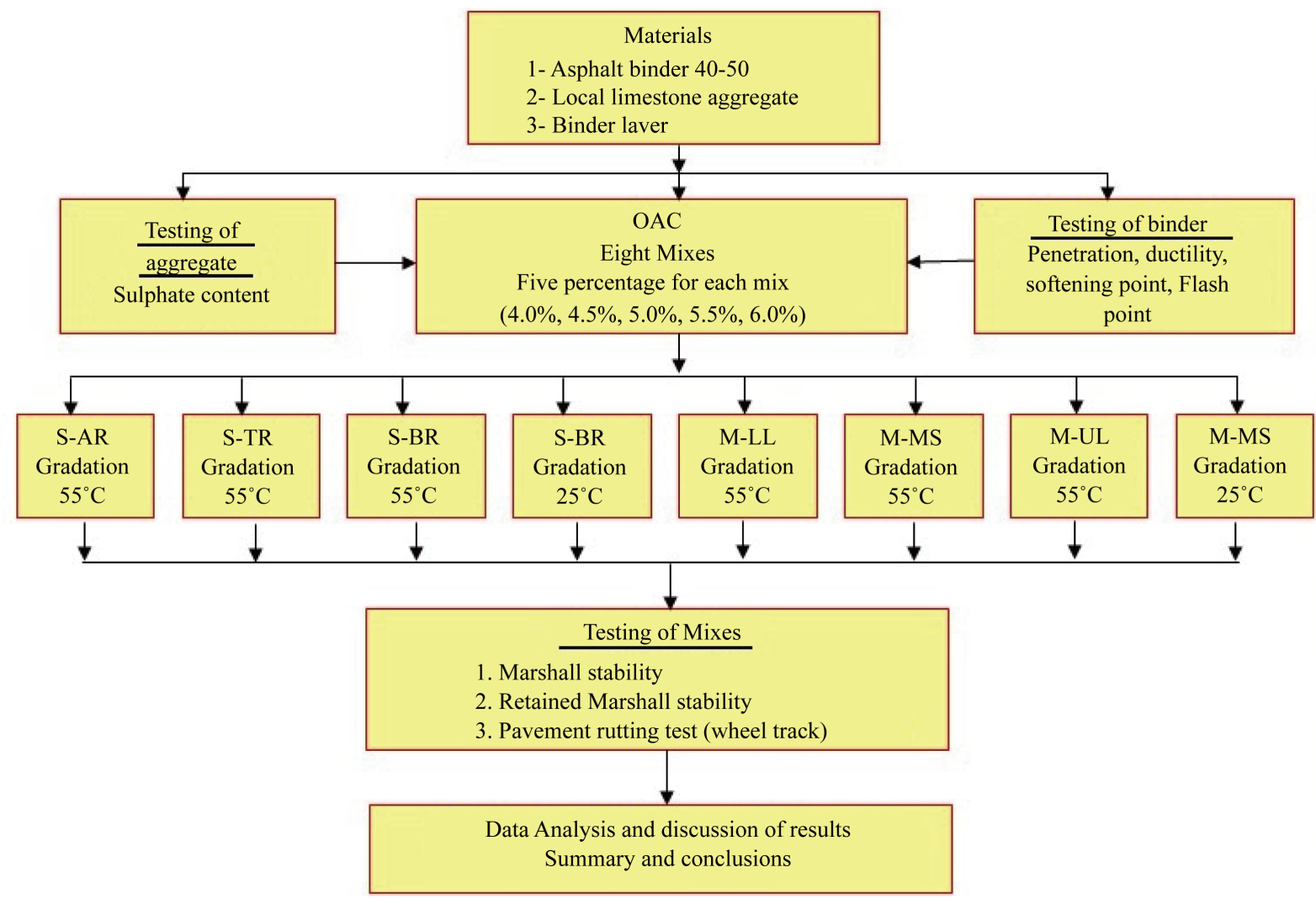

Figure 2. The research frame work (experimental programme).

Table 2. Optimum asphalt contents (OAC) for different aggregate gradations.

\begin{tabular}{|c|c|c|c|c|c|c|}
\hline Type of aggregategradation in HMA & S-AR & S-TR & S-BR & M-UL & M-MS & M-LL \\
\hline$\% \mathrm{OAC}$ & 5.2 & 4.9 & 4.7 & 5.1 & 5 & 4.8 \\
\hline
\end{tabular}




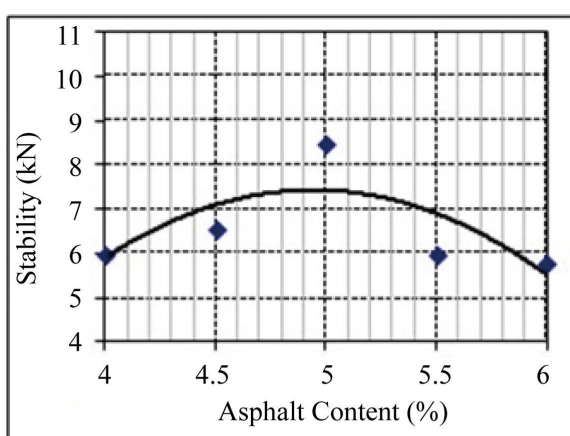

(a)

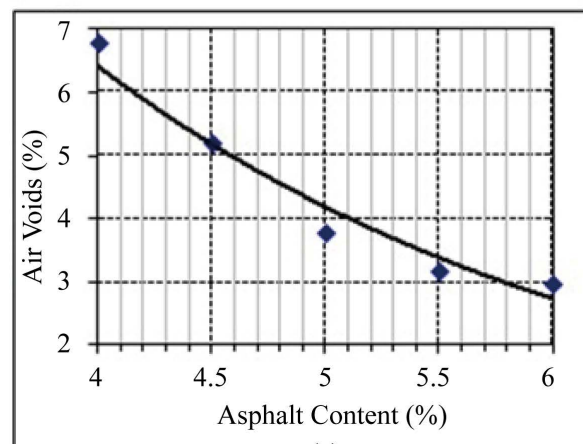

(c)

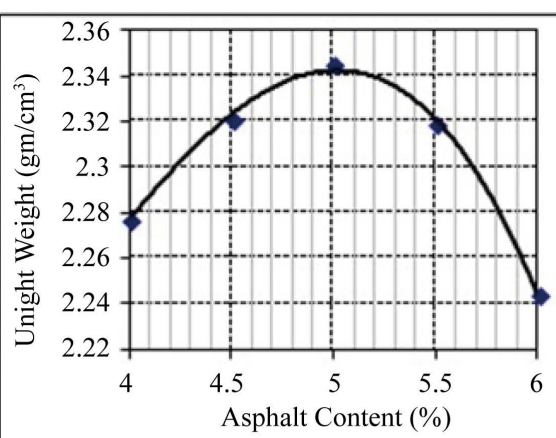

(b)

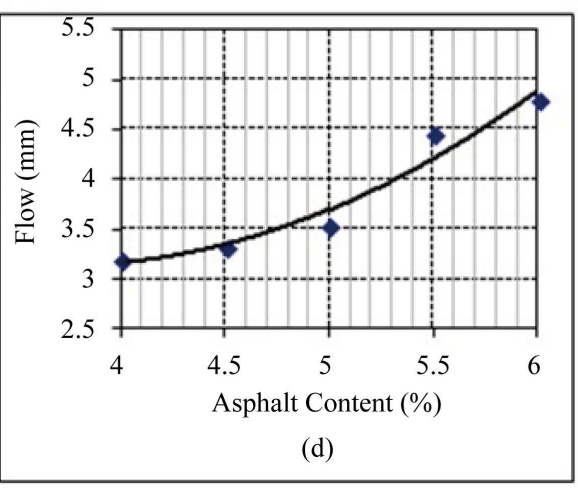

Figure 3. Determination of OAC according to Marshall method: (a) Relationship between Stability and \%AC; (b) Relationship between Unit weight and \%AC; (c) Relationship between Air void and \%AC; (d) Relationship between Flow and \%AC.
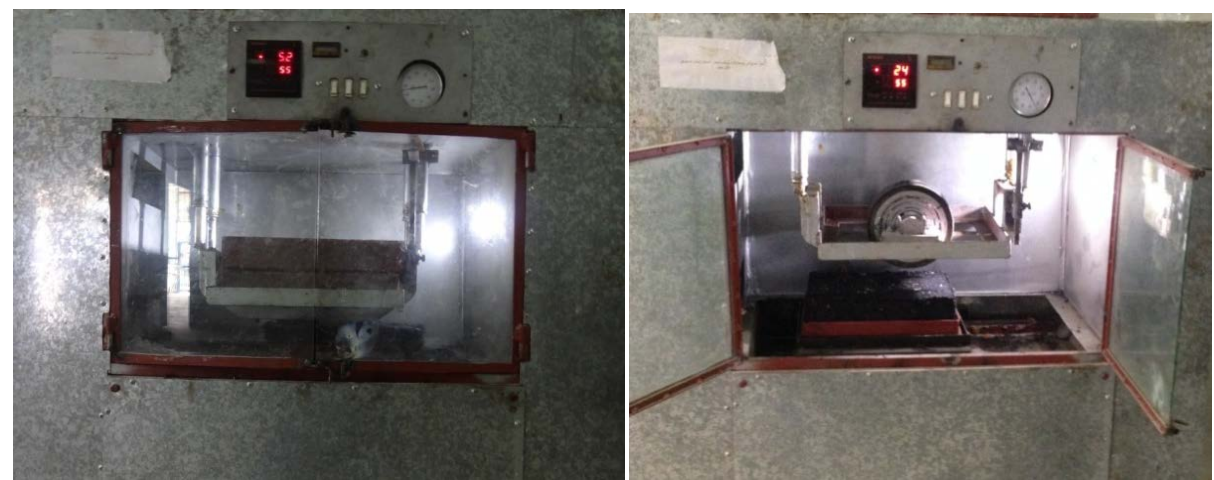

Figure 4. Pavement rutting testing machine.

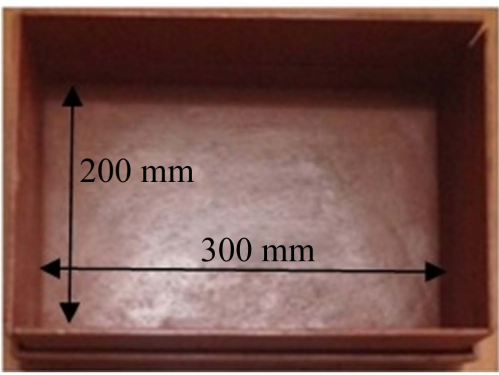

(a)

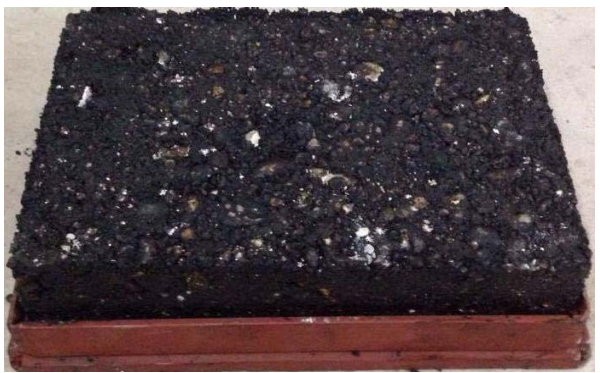

(b)

Figure 5. The parts of the used mould of specimen. (a) Complete mould; (b) Mould with specimen after removing upper part. 

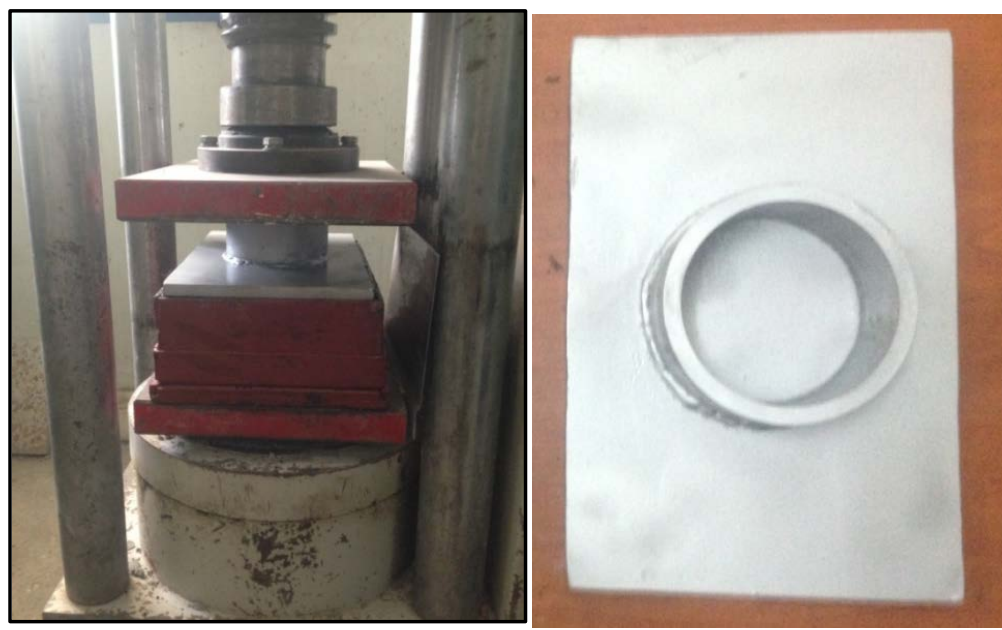

Figure 6. The compaction process of specimen.

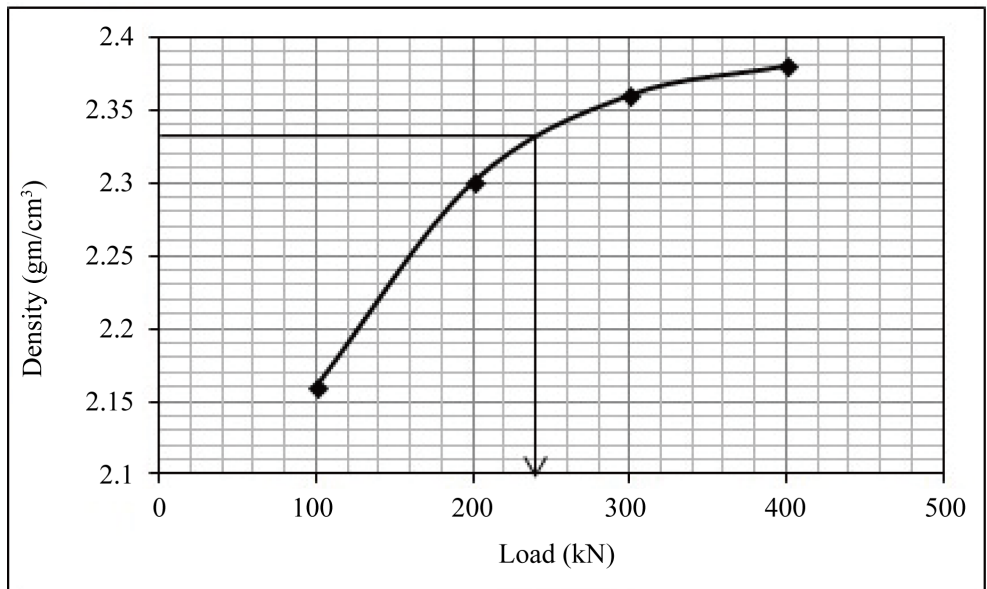

Figure 7. The selection of compaction loadaccording to density of Marshall specimen.

for 24 hours. Next, the specimens were cured in oven for 1 hour to reach the desired testing temperature, then it was placed in testing machine to start testing process. Load was applied on the wheel to produce a tire pressure of $560 \mathrm{kPa}$. Each specimen was loaded for 10,000 passes and the rutting depth was measured in the middle of specimen after each specific numbers of passes.

In addition to pavement rutting test, Marshall stability and Marshall retained stability were carried out on Marshall specimens for each type of mix according to selected aggregate gradation.

\section{Results and Discussion}

\subsection{Marshall Stability}

The Marshall stability test was conducted by testing three specimens for each aggregate gradation. The specimens were prepared and tested according to ASTM D 1559-89. The specimens were cured in water bath for 30 minute at $60^{\circ} \mathrm{C}$ then they were tested to measure the ultimate load. The test results illustrated in Figure 8 show that the specimens prepared with aggregate gradation according to Superpave method give more Marshall stability than those produced with aggregate gradation according to Marshall method. Also, the coarse aggregates yield more Marshall stability compared with finer particles. This can be attributed to stiffness of coarse aggregate and more interlock between the coarse aggregate particles. The mix that contained aggregate has a gradation pass through the restricted zone (S-TR) gives lower Marshall stability than the other types of Superpave base aggregate gradation mixes. This region is usually recommended to be removed from Superpave aggregate 


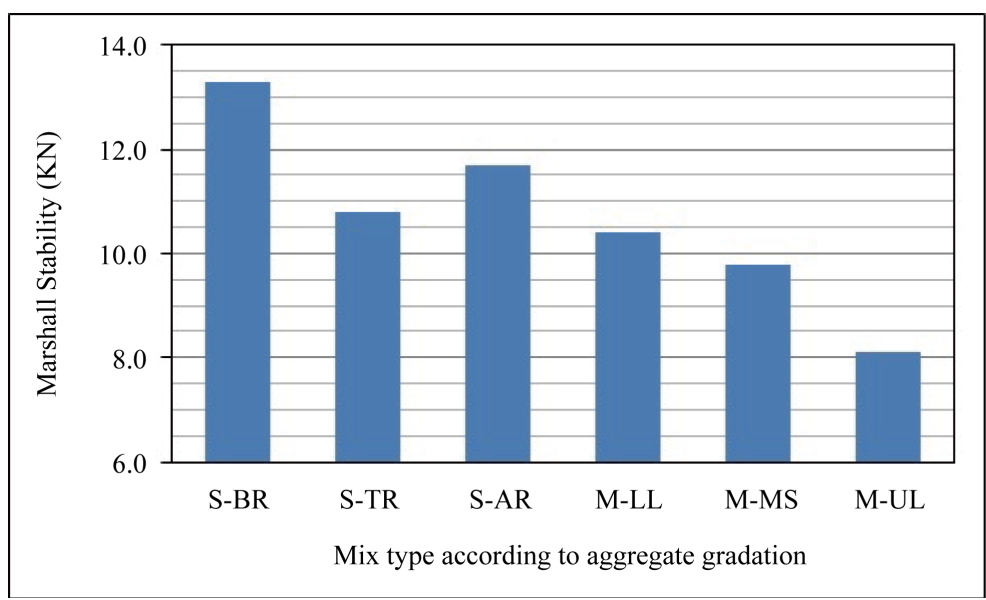

Figure 8. Test results of Marshall stability.

gradation [18].

\subsection{Index of Retained Strength}

Six specimens were prepared for each aggregate gradation according to [19] to have same specific gravity. Three of each six specimens were cured by immersion them in water bath for 24 hrs at temperature of $60^{\circ} \mathrm{C}$ (wet). The other three specimens were left for normal curing in an air bath for 4 hrs at temperature of $25^{\circ} \mathrm{C}$ (dry) [20]. Each group (three samples) was tested to measure the ultimate load. The index of retained strength was calculated according to Equation (1).

$$
\% \text { Index of retained strength }=\frac{S 1}{S 2} \times 100 \%
$$

S1: Compressive strength of wet specimens.

S2: Compressive strength of dry specimens.

Figure 9 presents the results of index of retained strength for all mixes. From that figure, it can be observed that the average percentage of index of retained strength for all specimens prepared with aggregate gradations based on Superpave method is more than these specimens prepared with aggregate gradations based on Marshall method. The other observation is that, the coarser aggregate gradation has less index of retained strength. This may be due to more air voids initiated with coarse aggregate. However, it still gives adequate level of index of retained strength.

\subsection{Rutting Test Results}

As mentioned earlier, six aggregate gradations were adopted for the current research. Three of these gradations were according to Marshall method as lower limit of specification (M-LL), mid-specification (M-MS), and upper limit of specification (M-UL). The other three represented aggregate gradations according to Superpave method as blow restricted zone (S-BR), through restricted zone (S-TR) and above restricted zone (S-AR).

The rutting depths were measured after 250, 500, 1000, 2000, 3000, 4000, 5000, and 10,000 passes. The testing machine was stopped after each specific number of passes at the middle of specimens to measure the rutting depth. Six specimens were tested at the temperature of $55^{\circ} \mathrm{C}$, this temperature represents the maximum prevailing temperature at Summer in most of middle east countries. Also; at such hot weather, the pavement rutting probability increases.

Figure 10 shows the results obtained of the six specimens prepared with different aggregate gradations according to Marshall and Superpave methods. The general trend of results for all specimens shows that for coarser aggregate gradation the rutting depth decreases. This behaviour attributes to better interlock of coarse aggregates that have rough surface texture (crushed) which gives more stability and stiffness for HMA. This finding agrees with other research in literature [21]-[23]. 


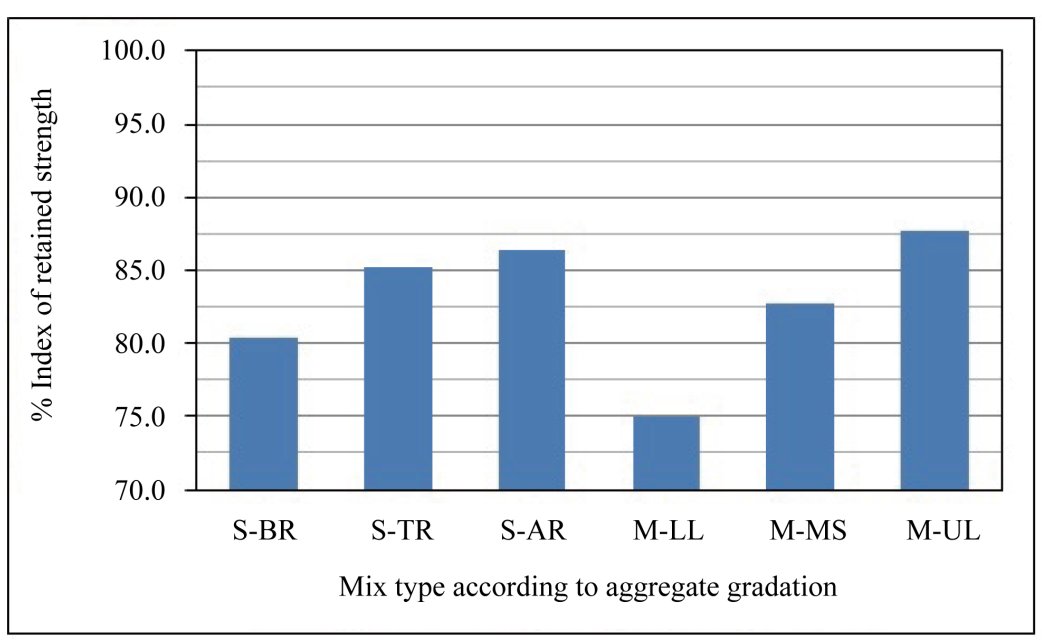

Figure 9. Index of retained strength.

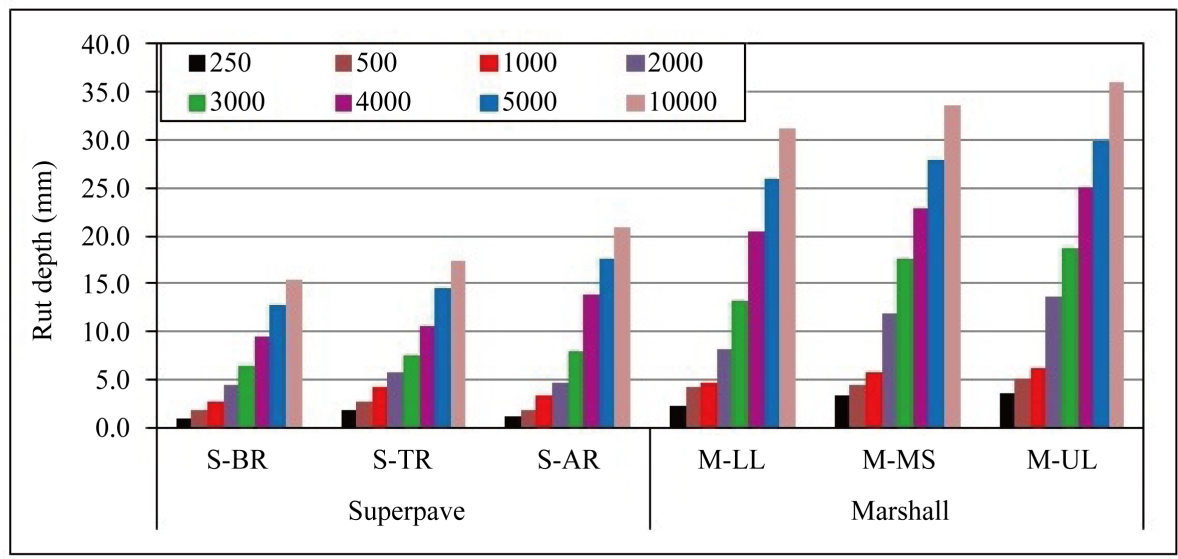

Figure 10. Rutting depth at temperature of $55^{\circ} \mathrm{C}$.

The most important point can be observed from Figure 10 is that the average rutting depth for specimens prepared according to Superpave aggregate gradations is about 50\% of those prepared according to Marshall aggregate gradations. This may be due to the restriction procedure follows by Superpave in selecting of aggregate gradation, which involve three additional sieves $(1.18 \mathrm{~mm}, 0.6 \mathrm{~mm}$ and $0.15 \mathrm{~mm})$ control the amount of rounded and finer aggregate which can cause the rutting. These sieves are missing in aggregate gradation according to Marshall procedure. The fine aggregate is graded using five sieves in Superpave procedure which can provide best and well gradation for aggregate at this important zone for rutting occurrence, while only two sieves were included for same zone in Marshall procedure. Unlike Marshall method, the continuous aggregate gradation in Superpave method provides the appropriate sizes of aggregate to fill unnecessary gaps in HMA and creates more contact points between the aggregate then consequently, increase the cohesion between the particles which gives more rutting resistance. The fine aggregate consists about $40 \%-50 \%$ of total aggregate in mixture, therefore the less control on this zone may allow for more inappropriate sizes to come in.

Figure 11 presents the photos of rutting depth of the six specimens at $55^{\circ} \mathrm{C}$, these photos clearly show the difference in rutting depth for the considered specimens.

Two specimens were tested at $25^{\circ} \mathrm{C}$ as shown in Figure 12, No clear differences or trend can be observed between these specimens. This can be attributed to moderate temperature and normal load, which reasonable does not cause rutting.

Figure 13 illustrates the photos of rutting depth of the two specimens at $25^{\circ} \mathrm{C}$. There is no clear difference in rutting depth between the two specimens. 


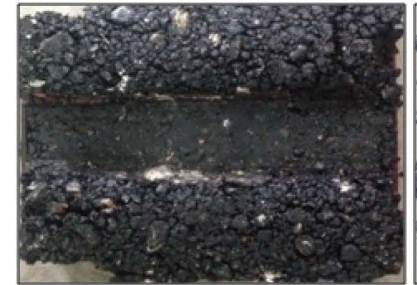

S-BR

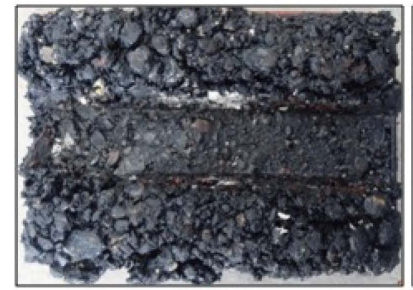

M-LL

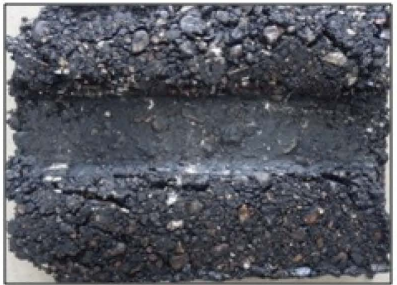

S-TR

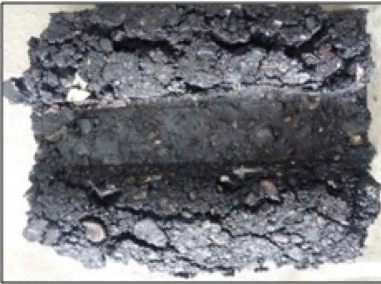

M-MS

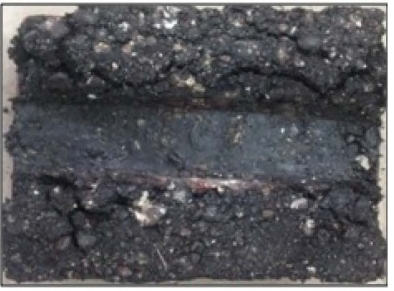

S-AR

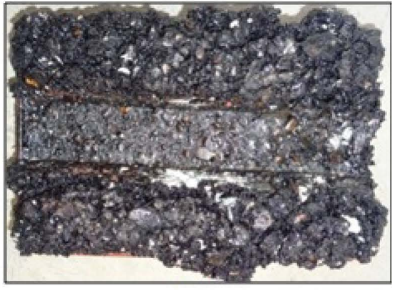

M-UL

Figure 11. Photos of specimens after 10,000 passes at $55^{\circ} \mathrm{C}$.

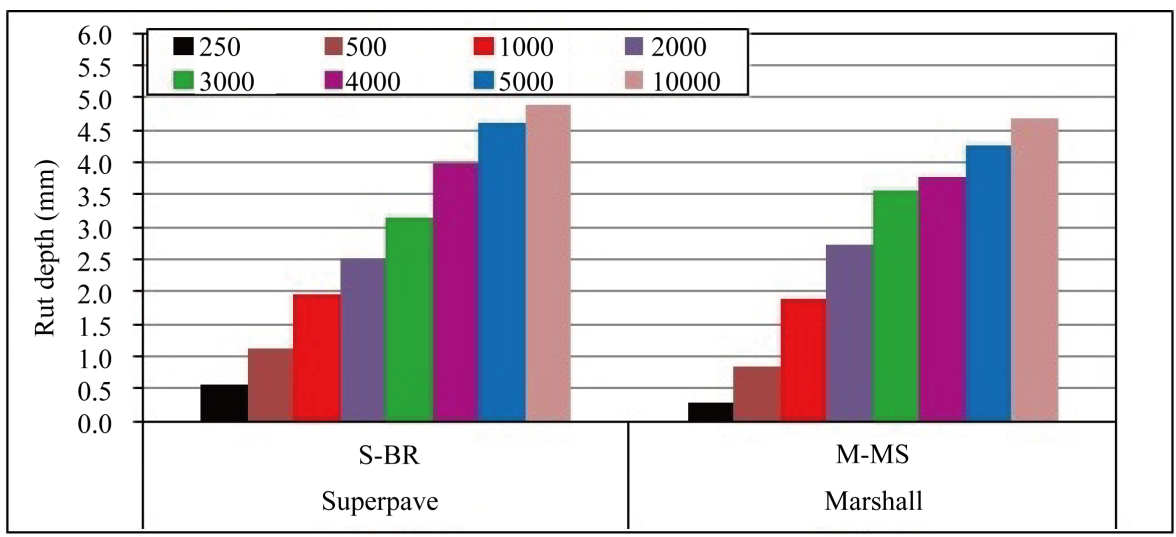

Figure 12. Rutting depth at temperature of $25^{\circ} \mathrm{C}$.

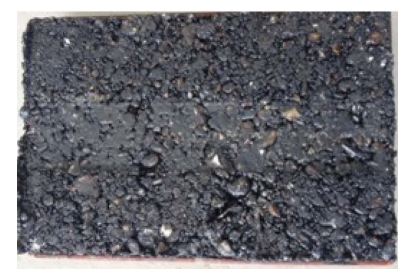

S-BR

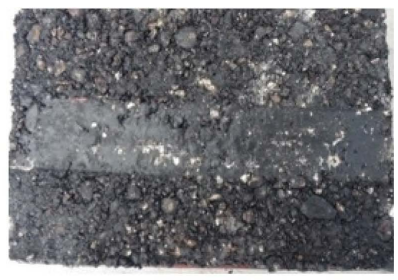

M-MS

Figure 13. Photos of specimens after 10,000 passes at $25^{\circ} \mathrm{C}$.

\section{Summary and Conclusions}

Extensive experimental investigations have been conducted to study the effect of aggregate gradation on permanent deformation (rutting depth) in flexible pavement. The investigations involve examine of both gradations formula according to Superpave and Marshall methods. The following conclusions were obtained from the study.

1) All mixes which designed according to Superpave aggregate gradation procedure gives more resistance to permanent deformation and less rutting depth (about 50\%) compared with mixes designed according to Marshall aggregate gradation procedure. This is because the restrictions on finer rounded particles in aggregate gradation procedure of Superpave method. 
2) Adopting of aggregate gradation procedure of Superpave method in Marshall method significantly improves rutting resistance. This point is very important in case of Superpave equipments are limited.

3) The coarser aggregate gradation provides more resistance to permanent deformation (rutting) due to more interlock and more stiffness.

4) Results of Marshall stability and an index of retained strength tests agree favourable with the pavement rutting test results.

\section{Recommendations for Future Studies}

According to the output of the study, the following recommendations can be suggested:

1) The effect of aggregate gradation on other parameters affecting pavement performance such as moisture induced damage and fatigue life of pavement needto be investigated.

2) New limits for Iraqi specification (SORB/R9) for aggregate gradation (in fine aggregate zone) can be suggested, comparative to that of Superpave aggregate gradation.

\section{References}

[1] Jitsangiam, P., Chindaprasirt, P. and Nikraz, H. (2013) An Evaluation of the Suitability of SUPERPAVE and Marshall Asphalt Mix Designs as They Relate to Thailand's Climatic Conditions. Construction and Building Materials, 40, 961970. http://dx.doi.org/10.1016/j.conbuildmat.2012.11.011

[2] ASTM D 1559 (1989) Standard Test Method for Resistance to Plastic Flow of Bituminous Mixtures Using Marshall Apparatus.

[3] Asi, I.M. (2007) Performance Evaluation of SUPERPAVE and Marshall Asphalt Mix Designs to Suite Jordan Climatic and Traffic Conditions. Construction and Building Materials, 21, 1732-1740. http://dx.doi.org/10.1016/j.conbuildmat.2006.05.036

[4] Kennedy, T.W., et al. (1994) Superior Performing Asphalt Pavements (Superpave): The Product of the SHRP Asphalt Research Program. Strategic Highway Research Program, National Research Council.

[5] Asphalt Institute (2001) SUPERPAVE Mix Design Series No. 2 (SP-2). Asphalt Institute Research Center, Lexington.

[6] Garber, N.J. (2009) Traffic and Highway Engineering. 4th Edition, University of Virgini.

[7] Button, J.W., Perdomo, D. and Lytton, R.L. (1990) Influence of Aggregate on Rutting in Asphalt Concrete Pavements. Transportation Research Record, 1259, 141-152.

[8] Ahlrich, R.C. (1996) Influence of Aggregate Gradation and Particle Shape/Texture on Permanent Deformation of Hot Mix Asphalt Pavements. DTIC Document.

[9] Bahia, H.U. and Stakston, A. (2003) The Effect of Fine Aggregate Angularity, Asphalt Content and Performance Graded Asphalts on Hot Mix Asphalt Performance. University of Wisconsin-Madison, Department of Civil and Environmental Engineering, 155.

[10] Moghaddam, T.B., Soltani, M. and Karim, M.R. (2014) Experimental Characterization of Rutting Performance of Polyethylene Terephthalate Modified Asphalt Mixtures under Static and Dynamic Loads. Construction and Building Materials, 65, 487-494. http://dx.doi.org/10.1016/j.conbuildmat.2014.05.006

[11] Moghaddam, T.B., Karim, M.R. and Abdelaziz, M. (2011) A Review on Fatigue and Rutting Performance of Asphalt Mixes. Scientific Research and Essays, 6, 670-682.

[12] Moghaddam, T.B., Soltani, M. and Karim, M.R. (2014) Evaluation of Permanent Deformation Characteristics of Unmodified and Polyethylene Terephthalate Modified Asphalt Mixtures Using Dynamic Creep Test. Materials \& Design, 53, 317-324. http://dx.doi.org/10.1016/j.matdes.2013.07.015

[13] Golalipour, A., Jamshidi, E., Niazi, Y., Afsharikia, Z. and Khadem, M. (2012) Effect of Aggregate Gradation on Rutting of Asphalt Pavements. Procedia-Social and Behavioral Sciences, 53, 440-449. http://dx.doi.org/10.1016/j.sbspro.2012.09.895

[14] Han, D., Wei, L. and Zhang, J. (2016) Experimental Study on Performance of Asphalt Mixture Designed by Different Method. Procedia Engineering, 137, 407-414. http://dx.doi.org/10.1016/j.proeng.2016.01.275

[15] Xue, Y., et al. (2009) Utilization of Municipal Solid Waste Incineration Ash in Stone Mastic Asphalt Mixture: Pavement Performance and Environmental Impact. Construction and Building Materials, 23, 989-996. http://dx.doi.org/10.1016/j.conbuildmat.2008.05.009

[16] Arslan, D., Guru, M. and Cubuk, M.K. (2014) Preventing of Rutting and Crackings in the Bituminous Mixtures by Monoethylene and Diethylene Glycol Based Synthetic Polyboron Compounds. Construction and Building Materials, 50, 102-107. http://dx.doi.org/10.1016/j.conbuildmat.2013.09.039 
[17] State Corporation for Roads and Bridges (2003) General Specification for Roads and Bridges (SORB/R9)—Hot Mix Asphaltic Concrete Pavement. Department of Planning and Studies, Republic of Iraq, Ministry of Housing and Construction, Editor. Revised Edition, Addendum No.3, Baghdad.

[18] Al-Mistarehi, B. (2014) Superpave System versus Marshall Design Procedure for Asphalt Paving Mixtures (Comparative Study). Global Journal of Research in Engineering, 14, 45-52.

[19] ASTM D1074 (2002) Standard Test Method for Compressive Strength of Bituminous Mixtures.

[20] ASTM D1075 (2007) Standard Test Method for Effect of Water on Compressive Strength of Compacted Bituminous Mixtures.

[21] Pan, T., Tutumluer, E. and Carpenter, S.H. (2006) Effect of Coarse Aggregate Morphology on Permanent Deformation Behavior of Hot Mix Asphalt. Journal of Transportation Engineering, 132, 580-589. http://dx.doi.org/10.1061/(ASCE)0733-947X(2006)132:7(580)

[22] Roberts, F.L., et al. (1996) Hot Mix Asphalt Materials, Mixture Design and Construction. 2nd Edition, NAPA Education Foundation, Lanham.

[23] Li, P., Jiang, K. and Li, H.S. (2012) High-Temperature Stability of Asphalt Mixture with the Influence of Styrene Butadiene Styrene. Procedia-Social and Behavioral Sciences, 43, 842-848. http://dx.doi.org/10.1016/j.sbspro.2012.04.159

\section{Submit or recommend next manuscript to SCIRP and we will provide best service for you:}

Accepting pre-submission inquiries through Email, Facebook, LinkedIn, Twitter, etc.

A wide selection of journals (inclusive of 9 subjects, more than 200 journals)

Providing 24-hour high-quality service

User-friendly online submission system

Fair and swift peer-review system

Efficient typesetting and proofreading procedure

Display of the result of downloads and visits, as well as the number of cited articles

Maximum dissemination of your research work

Submit your manuscript at: http://papersubmission.scirp.org/ 